\title{
Papel de la vacuola parasitófora de macrófagos de ratón infectados por Leishmania amazonensis en la adquisición de moléculas
}

\author{
Tania M. Cortázar ${ }^{1,2}$, Joselín Hernández ${ }^{1,2}$, María Clara Echeverry ${ }^{1,3}$, Marcela Camacho ${ }^{1,2}$ \\ ${ }^{1}$ Laboratorio de Biofísica, Centro Internacional de Física, Universidad Nacional de Colombia, Bogotá, D.C., \\ Colombia \\ 2 Departamento de Biología, Facultad de Ciencias, Universidad Nacional de Colombia, Bogotá, D.C., Colombia. \\ ${ }^{3}$ Laboratorio de Parasitología, Departamento de Salud Pública, Facultad de Medicina, Universidad Nacional \\ de Colombia, Bogotá, D.C., Colombia
}

Introducción. Leishmania son parásitos intracelulares de macrófagos, confinados en compartimentos denominados vacuolas parasitóforas. La permeabilidad de este compartimento depende de su interacción con el tráfico vesicular y transportadores presentes en su membrana. Objetivo. En este trabajo se estudió la permeabilidad de la membrana de la vacuola parasitófora en la línea celular J774.A1 infectada con Leishmania amazonensis, in situ y en compartimentos aislados.

Materiales y métodos. El aislamiento de vacuolas parasitóforas se hizo por gradiente de densidad. La permeabilidad de la membrana de estas se valoró por distribución de sondas fluorescentes y electrofisiología. Para establecer indirectamente el transporte de protones se usó naranja de acridina. La presencia de transportadores $A B C$ sensibles a probenecid se estableció con amarillo lucifer y calceína. Por primera vez con la técnica de patch-clamp se registraron corrientes en la membrana de este compartimento aislado.

Resultados. La vacuola parasitófora colorea de rojo con naranja de acridina indicando un $\mathrm{pH}$ ácido. Concentra amarillo lucifer a través de un transportador sensible a probenecid, pero excluye la sonda calceína. Vacuolas aisladas se marcan de rojo con naranja de acridina y concentran amarillo lucifer a través de un transportador sensible a probenecid. Estas vacuolas excluyeron calceína y presentaron en su membrana una corriente iónica que se activa a diferencias de potencial cercanas a $60 \mathrm{mV}$, con una conductancia de $46 \pm 3$ pS.

Conclusiones. Se pueden aislar vacuolas parasitóforas con propiedades de permeabilidad que preservan mecanismos de transporte similares a los encontrados in situ. Se registra por primera vez la presencia de una corriente iónica poco selectiva en la membrana de este compartimiento.

Palabras clave: Leishmania, membranas intracelulares, permeabilidad, proteínas de transporte de anión, transporte iónico, canales iónicos.

Role of the parasitophorous vacuole of murine macrophages infected with Leishmania amazonensis in molecule acquisition

Introduction. Leishmania are intracellular parasites of macrophages, confined into compartments known as parasitophorous vacuoles. The permeability of this compartment depends on its interaction with the endocytic pathway and transport proteins present on its membrane.

Objective. The membrane permeability of the parasitophorous vacuole was studied in J774.A1macrophage like cells infected with Leishmania amazonensis, in situ and on isolated compartments.

Materials and methods. The parasitophorous vacuoles were isolated by density gradients. Fluorescent probe distribution and electrophysiological recordings were used to determine parasitophorous vacuole membrane permeability. Proton transport was evaluated indirectly by acridine orange staining. Probenecid sensitive $A B C$ transporters were detected using the fluorescent probes lucifer yellow and calcein. For the first time ion currents were recorded on the membrane of isolated parasitophorous vacuoles using the patch clamp technique. 
Results. The parasitophorous vacuole stains red with acridine orange indicating an acidic compartment. It concentrates lucifer yellow by means of a probenecid sensitive transporter but excludes calcein. Isolated vacuoles stained red with acridine orange and concentrated lucifer yellow by means of a probenecid sensitive transporter. These vacuoles excluded calcein and showed an ion current in their membrane which is activated at potentials close to $60 \mathrm{mV}$ with a mean conductance of $46 \pm 3$ pS.

Conclusions. Isolated parasitophorous vacuoles with permeability properties preserving transport mechanisms similar to those found in situ can be purified. A poorly selective ion current on the parasitophorous vacuole membrane is reported for the first time.

Key words: Leishmania, intracellular membranes, permeability, anion transporter proteins, ion transport, ion channels.

Leishmania spp. son parásitos intracelulares obligatorios. Después de entrar al hospedero mamífero, el parásito es fagocitado por macrófagos $\mathrm{y}$, posteriormente, confinado a un compartimiento denominado vacuola parasitófora que se caracteriza por ser ácido y rico en hidrolasas (1). Asumimos que para su supervivencia el parásito depende de la interacción de las tres membranas concéntricas presentes: la membrana plasmática del macrófago, la membrana de la vacuola parasitófora y su membrana plasmática.

La permeabilidad de la vacuola parasitófora de Leishmania está determinada por la capacidad de este compartimiento de interactuar con la vía endocítica y la expresión de transportadores en su membrana. La membrana de la vacuola parasitófora se fusiona con vesículas provenientes de la ruta endocítica desde la membrana plasmática y moléculas que entran por endocitosis de fase líquida, como el dextrán, o por endocitosis mediada por receptores, como la albúmina, se sitúan con Leishmania (2). Además, la membrana de la vacuola parasitófora se fusiona por la ruta mediada por receptores de manosa-6-fosfato (2) y la de la autofagia (3). La evidencia de la expresión de los transportadores en la membrana de la vacuola parasitófora está dada por el pH ácido de

Correspondencia:

Marcela Camacho, Laboratorio de Biofísica, Centro Internacional de Física, Edificio de Programas Especiales "Manuel Ancízar", Ciudad Universitaria, apartado aéreo 4948, Bogotá, D.C., Colombia.

Telefax: (571) 368 1517, 3690487 y 571 4286; fax: (571) 3681335.

mcamacho@cable.net.co y mmcamachon@unal.edu.co

Recibido: 28/07/05; aceptado: 10/02/06 su luz en donde el transporte de protones está a cargo de una ATPasa vacuolar (4) y por la expresión de transportadores aniónicos de la superfamilia de transportadores $\operatorname{ABC}(3,5)$.

En este estudio se indaga el papel de la membrana de la vacuola parasitófora que contiene Leishmania amazonensis en el transporte de moléculas entre el citoplasma de la célula hospedera y la luz de la vacuola parasitófora. Se confirma evidencia previa que indica acumulación de protones y expresión de transportadores ABC. Se reporta un protocolo para el aislamiento de la vacuola parasitófora que permite mantener las propiedades de permeabilidad estudiadas en compartimientos in situ, y se presentan, por primera vez, registros electrofisiológicos sobre la membrana de este compartimiento que muestran una corriente iónica poco selectiva.

\section{Materiales y métodos}

\section{Parásitos}

Se cultivaron promastigotes de $L$. amazonensis (FLA/BR/67/PH8), gentilmente donados por Nancy Gore Saravia, CIDEIM, Cali, Colombia, a $24^{\circ} \mathrm{C}$ en medio Schneider (Sigma) con suplemento de suero fetal bovino al $10 \%$. Los parásitos se cultivaron hasta alcanzar su fase estacionaria $\left(10^{7}\right)$ y se concentraron para la infección o se diluyeron para mantener el cultivo.

\section{Célula huésped}

La línea de macrófagos peritoneales de ratón J774.A1 ( EECACC № 91051511) se mantuvo en monocapa al $80 \%$ de confluencia en cajas de cultivo de $25 \mathrm{~cm}^{2}$ en medio de cultivo RPMI 1640 (Sigma) con suplemento de suero fetal bovino al $10 \%$ (Hyclone) a $37^{\circ} \mathrm{C}$ y $5 \%$ de $\mathrm{CO}_{2}$. 


\section{Infección y fagocitosis}

Se expusieron las células J774.A1 a promastigotes de $L$. amazonensis en fase estacionaria o a partículas de látex de $3 \mu \mathrm{m}$ de diámetro, en una proporción de 1 a 10 y se mantuvieron a $35^{\circ} \mathrm{C}$ y $5 \%$ de $\mathrm{CO}_{2}$ por 4 horas (6). El excedente de parásitos o partículas de látex se removió por lavado con RPMI. Posteriormente, los cultivos se mantuvieron a $35^{\circ} \mathrm{C}$ y $5 \%$ de $\mathrm{CO}_{2}$ hasta por 5 días después de la infección.

\section{Aislamiento de vacuolas parasitóforas de L. amazonensis}

En este estudio se partió de $5 \times 10^{6}$ macrófagos, con porcentajes de infección a las 48 horas de $75,5 \pm 0,8 \%$ para aislar vacuolas parasitóforas (7). Este tiempo de infección se eligió por el volumen de la vacuola parasitófora y el comportamiento durante la purificación. Tiempos menores de infección mostraban vacuolas parasitóforas de menor tamaño pero mayor variabilidad lo que dificultaba la separación en una fracción y, luego de las 72 horas después de la infección, los compartimientos aislados eran muy frágiles.

Para el aislamiento se siguió un procedimiento modificado a partir del descrito por Chakraborty et al. (8). En éste se combina un choque osmótico en una solución hipotónica con ruptura mecánica de la membrana plasmática del macrófago. Una vez que se lisan las células, el homogenizado se separa en gradientes de densidad (8).

A las 48 horas después de la infección, se removieron mecánicamente las células infectadas con $L$. amazonensis de la caja de cultivo en 2,5 $\mathrm{ml}$ de medio de lisis, compuesto por $20 \mathrm{mM}$ HEPES, 0,5mM EGTA, 0,25M sacarosa, 0,1\% gelatina (Sigma G-9382), pH 7, más una mezcla de inhibidores de proteasas, así: ácido etilendiamino tetraacético, sal de sodio (EDTA) $0,5 \mathrm{mM}$; etilen glicol bis(2-aminoetiléter)- $N, N, N^{\prime}, N^{\prime}$ ácido tetracético (EGTA) $0,5 \mathrm{mM}$, transepoxisuccinil-L-leucilamido-(4-guanidino)-butano (E-64) $2 \mu \mathrm{M}, \mathrm{N}$ - $\alpha$-p-tosil-L-lisina clorometilcetona $\mathrm{HCl}$ (TLCK) $0,2 \mu \mathrm{M}$, leupeptina $0,1 \mathrm{mM}$ y pepstatin $0,1 \mu \mathrm{M}$.

Una vez en el medio de lisis, las células infectadas fueron sometidas a ruptura mecánica por medio de una jeringa con aguja calibre $27 \mathrm{G}$ en un tubo Falcon de $15 \mathrm{ml}$ y sobre hielo durante 10 minutos. El procedimiento se controló por microscopía de luz hasta lograr el $90 \%$ de lisis celular.

Para remover células intactas y núcleos del homogenizado, la suspensión se diluyó a $10 \mathrm{ml}$ en solución tamponada de lisis y se centrifugó a $50 \mathrm{~g}$ por 10 minutos a $4^{\circ} \mathrm{C}$. El sobrenadante se llevó a un gradiente discontinuo de sacarosa (8). Con este tipo de gradiente no fue posible separar compartimentos que preservaran las características de las vacuolas parasitóforas. Por lo tanto, se modificó así: un colchón inferior de $60 \%$ de sacarosa, más colchones de $1 \mathrm{ml}$ de Percoll (partículas coloidales de sílica cubiertas con polivinilpirrolidona) en concentraciones variables en una solución (en mM) de 145 de $\mathrm{NaCl}, 5$ de $\mathrm{KCl}$ y 10 de HEPES. Este gradiente se centrifugó a $3.500 \mathrm{~g}$ por 25 minutos a $4^{\circ} \mathrm{C}(7)$.

Las fracciones recolectadas se visualizaron por microscopía de luz y aquéllas en las que se ubicaron vacuolas que contenían parásitos, se lavaron en una solución (en mM) $145 \mathrm{NaCl}, 5 \mathrm{KCl}$, 10 HEPES y $2 \mathrm{MgCl}_{2}, \mathrm{pH} 7,34(\mathrm{KOH} 1 \mathrm{~N})-310$ mOsm y se concentraron por centrifugación a $2.000 \mathrm{~g}$ por 10 minutos. El sedimento con $0,5-1 \times 10^{3}$ compartimientos aislados se resuspendió suavemente en diferentes soluciones dependiendo del experimento que se iba a realizar.

\section{Microscopía de los compartimentos aislados}

Para determinar la naturaleza del compartimiento aislado se realizaron inicialmente observaciones morfológicas con microscopía de luz siguiendo los criterios descritos por Lang para vacuolas parasitóforas de Leishmania (9): espacio delimitado por una membrana, con un diámetro entre 10 y $20 \mu \mathrm{m}$, con parásitos en su interior, generalmente, polarizados hacia la membrana del compartimiento.

Una aproximación al pH de los compartimentos y la detección de ácidos nucleicos parasitarios en su interior se hizo mediante la sonda metacromática naranja de acridina en concentraciones entre 4 y $8 \mu \mathrm{M}$ incubando los compartimentos aislados en los diferentes gradientes, durante 15 minutos en la oscuridad. 
Simultáneamente, se incubaron células infectadas en las mismas condiciones. La marcación de los compartimentos vesiculares purificados en cada uno de los gradientes se visualizó en microscopio de fluorescencia con un juego de filtros $480 \mathrm{~nm} /$ $520 \mathrm{~nm}$.

\section{Actividad enzimática en los compartimentos aislados}

La actividad de $\beta$-glucoronidasa, enzima lisosómica, se determinó mediante la incubación de los productos aislados de los diferentes gradientes, en $0,1 \mathrm{M}$ de acetato de sodio, $\mathrm{pH} 4,4$ y $0,25 \%$ Tritón $X-100$, y usando como sustrato $1 \mathrm{mM}$ de 4-metillimbreliferil-2-acetamido-2-deoxi- $\beta$ D-glucopitanósido. La reacción se determinó por espectrofotometría a $448 \mathrm{~nm}$.

\section{Carga de sondas fluorescentes dentro del citoplasma de células $\mathbf{J 7 7 4 . 1}$}

Se expusieron células J744.A1 (control, expuestas a partículas de látex 0 infectadas) adheridas a laminillas de vidrio por 24 horas a dos sondas aniónicas fluorescentes de diferente tamaño como se describe a continuación. Antes de las observaciones, bajo microscopía de luz en un microscopio invertido Zeiss IM-35, las células se lavaron tres veces con medio RPMI. La adquisición de imágenes se llevó a cabo con una videocámara CCD modelo IC-100 acoplada al microscopio y con el programa AIW 2.2. También se tomaron fotografías con cámara fotográfica Canon EOS 3000 QD.

Amarillo lucifer (521 da). Las células se expusieron a esta sonda, la cual absorbe a $427 \mathrm{~nm}$ y emite a $535 \mathrm{~nm}$ (Sigma), a una concentración de $0,5 \mathrm{mg} /$ $\mathrm{ml}$, más ATP $5 \mathrm{mM}$ y ácido plurónico $5 \mu \mathrm{M}$ en RPMI, durante 5 minutos. La marcación fluorescente se detectó usando un juego de filtros de $480 \mathrm{~nm} / 520$ $\mathrm{nm}$; se realizaron observaciones a los $5,10,30 \mathrm{y}$ 60 minutos después de la carga. También se realizó la carga de amarillo lucifer en las mismas condiciones y en presencia de $5 \mathrm{mM}$ de probenecid, un inhibidor de transportadores $A B C$.

Calceína/AM (995 da). Las células se expusieron a esta sonda, la cual absorbe a $494 \mathrm{~nm}$ y emite a $517 \mathrm{~nm}$ (Molecular probes, Eugene, Oregon), a

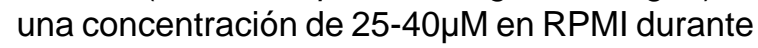

5 minutos. La fluorescencia se evidenció usando un juego de filtros de $480 \mathrm{~nm} / 520 \mathrm{~nm}$; se realizaron observaciones a los $5,10,30$ y 60 minutos después de la carga.

\section{Carga de sondas fluorescentes en vacuolas parasitóforas aisladas}

Las vacuolas parasitóforas aisladas en una solución (en mM) de $140 \mathrm{~K}$ glutamato, $2 \mathrm{KCl}, 5$ EGTA-K, 0,5 $\mathrm{CaCl}_{2}, 4 \mathrm{MgCl}_{2}$, 10 HEPES-K, 3 ATP$\mathrm{Na}_{2}, 0,5$ GTP-Na (pH 7,34, 300mOsm), para mantener condiciones iónicas similares a las del citoplasma, se cargaron con naranja de acridina para verificar el $\mathrm{pH}, \mathrm{y}$ con amarillo lucifer para verificar su viabilidad (3). Así mismo, se cargaron con calceína $(25 \mu \mathrm{M})$, se incubaron con la sonda durante 5 minutos a $35^{\circ} \mathrm{C}$ y $5 \% \mathrm{CO}_{2}$, y se lavaron una vez.

Calceína sal de potasio (622,5 da). Las células se inyectaron con $25 \mu \mathrm{M}$ de esta sonda disuelta en una solución cuya composición era (en mM) de $145 \mathrm{NaCl}, 5 \mathrm{KCL}, 1 \mathrm{CaCl}_{2}, 2 \mathrm{MgCl}_{2}, 10 \mathrm{HEPES}$ $\mathrm{Na}, 5$ glucosa, $\mathrm{pH} 7,2,300$ mOsm, mediante micropipetas hechas de capilares de hematocrito no heparinizados (Fisher Scientific No. 02-668-6) cuyas resistencias variaron entre $3-5 \mathrm{M} \Omega$ y usando la configuración de célula entera de la técnica de electrofisiología patch clamp (10). En otras palabras, antes de perforar la membrana de la vacuola parasitófora se obtuvo un sello de alta resistencia entre la membrana de la vacuola parasitófora y la micropipeta de vidrio. Una vez alcanzada una resistencia superior a $1 \mathrm{G} \Omega$, se aplicó presión negativa sobre la membrana hasta lograr la ruptura controlada de ésta, al tiempo que se obtenía registro visual en fluorescencia con la cámara digital y el programa Axon Imaging Workbench 2.2.

\section{Registros electrofisiológicos}

Las técnicas de electrofisiología se usan para la detección de las propiedades eléctricas de la membrana tales como potenciales de membrana y corrientes iónicas. El montaje para el registro de estas propiedades constó de un amplificador Axopatch 1-C (Axon Instruments, Foster City, CA). Los pulsos de voltaje generados y las corrientes obtenidas, se digitalizaron con una interfase 
análogo-digital, Digidata 1200 (Axon Instruments, Foster City, CA). Las señales se filtraron y almacenaron en una computadora compatible con IBM.

Para la generación de los potenciales y la obtención de los registros, se utilizó el paquete de programa electrofisiológico Pclamp6. Utilizando la configuración de vacuola adherida similar a la de célula adherida de la técnica de patch clamp (10), se hicieron registros en vacuolas parasitóforas aisladas suspendidas en una solución (en mM) de $145 \mathrm{NaCl}, 5 \mathrm{KCl}, 1 \mathrm{CaCl}_{2}, 10$ HEPES. En esta configuración se acerca la punta de una micropipeta de vidrio a la membrana de la vacuola parasitófora y ejerciendo presión negativa se genera un sello de alta resistencia $(>1 G \Omega)$. De esta manera, se pueden registrar los canales iónicos presentes en la porción de membrana que queda en la luz de la micropipeta.
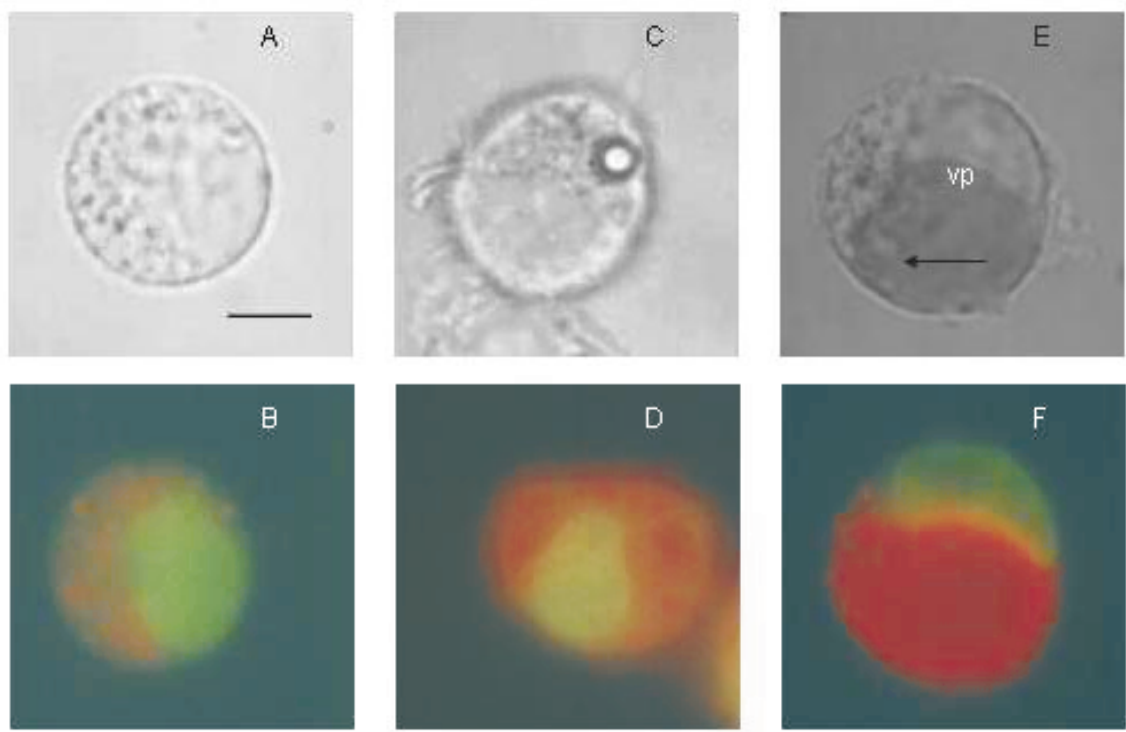

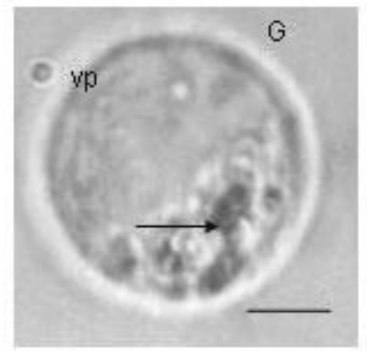

Las micropipetas de registro se hicieron con capilares de borosilicato cuyas resistencias variaron entre 3 y $5 \mathrm{M} \Omega$ en una solución (en $\mathrm{mM}$ ) de $145 \mathrm{NaCl}, 5 \mathrm{KCl}, 1 \mathrm{CaCl}_{2}, 10$ HEPES, 15 EGTA, tratando de conseguir condiciones electroquímicamente simétricas y potenciales de reversión cercanos a 0 para los iones más importantes. Los registros se analizaron con el programa Pclamp6 (Axon Instruments) y se graficaron con el programa Origin 7SR (OriginLag Corporation, Northampton, MA, USA).

\section{Resultados}

\section{Permeabilidad de la vacuola parasitófora a los protones}

La estructura de la sonda naranja de acridina hace que esta pueda pasar fácilmente a través de las membranas. Por lo tanto, permea la membrana del macrófago y al entrar en el núcleo se intercala

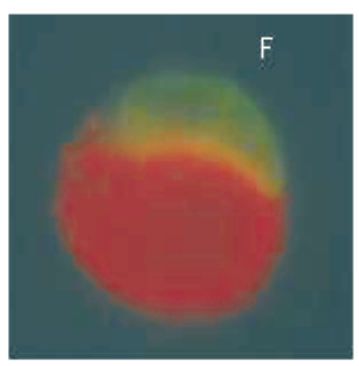

Figura 1. Permeabilidad a protones medida por distribución de la sonda fluorescente naranja de acridina. Células J774.A1 control, luego de fagocitosis de partículas de látex, infectadas por Leishmania amazonensis, o vacuolas parasitóforas aisladas, se cargaron con naranja de acridina a una concentración de $4-8 \mu \mathrm{g} / \mathrm{ml}$ y se observaron por microscopía de fluorescencia. A. Macrófago control, microscopía de luz. B. Macrófago control, después de la carga de la sonda. C. Macrófagos luego de la fagocitosis de partículas de látex, microscopia de luz. D. Macrófagos luego de la fagocitosis de partículas de látex, después de la carga de la sonda. E. Macrófagos infectados por L. amazonensis 48 horas después de la infección, microscopia de luz. F. Macrófagos infectados por L. amazonensis 48 horas después de la infección, después de la carga de la sonda. G. Vacuola parasitófora aislada, microscopía de luz. H. Vacuola parasitófora después de la carga de la sonda. Los datos son experimentos representativos de 10.

Barra en A-F: $8 \mu \mathrm{m}$; en G-H: $5 \mu \mathrm{m}$; vp: vacuola parasitófora; flechas: parásitos. Nótese que la coloración verde es la marcación de ácidos nucleicos y la roja indica compartimientos con pH ácido. 
entre los ácidos nucleicos emitiendo una fluorescencia verde. Sin embargo, al pasar a compartimientos ricos en $\mathrm{H}^{+}$como la vacuola parasitófora, adquiere carga neta positiva, su movilidad disminuye y su espectro de emisión cambia emitiendo en el rango del rojo. Esta marcación, indirectamente, sugiere la presencia de mecanismos que median el transporte de protones y generan un gradiente de este ion con respecto al citoplasma del macrófago.

En la figura 1 se observa un macrófago control (figura $1 \mathrm{~A}$ ) en donde la coloración verde corresponde al núcleo y el punteado rojo a compartimentos de la vía endocítica cuyo $\mathrm{pH}$ es ácido (figura 1B). Los macrófagos que fagocitaron látex o fueron infectados por Leishmania se pueden identificar por la presencia de partículas (figura 1C) o vacuolas de gran volumen con parásitos de tamaño similar a las partículas de látex en su interior. Las partículas de látex y Leishmania se ubican en compartimentos, fagosomas (figura 1D) y vacuolas parasitóforas (figuras 1E$1 \mathrm{H}$ ), respectivamente, cuyo $\mathrm{pH}$ es ácido lo que se evidencia por la coloración roja obtenida luego de la marcación con naranja de acridina.

\section{Permeabilidad mediada por transportadores en la membrana de la vacuola parasitófora}

Se cargaron células J744.A1 control, expuestas a partículas de látex o infectadas con $L$. amazonensis, con las sondas amarillo lucifer y
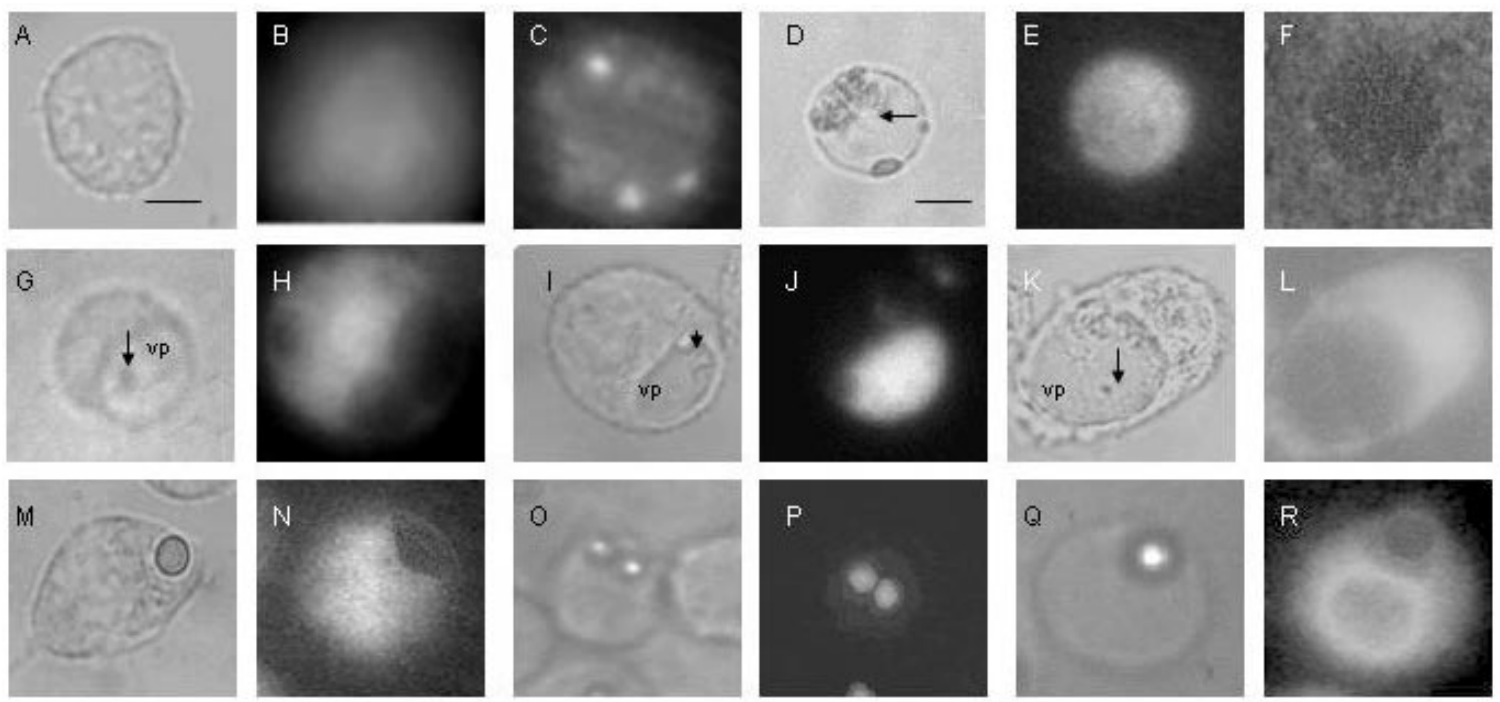

Figura 2. Permeabilidad de la vacuola parasitófora a través de trasportadores $A B C$ determinada por distribución de la sonda fluorescente amarillo lucifer. Células J774.A1 control (A-C), vacuolas parasitóforas aisladas (D-F), células infectadas por $L$. amazonensis (G-L) o luego de fagocitosis de partículas de látex (M-R), se cargaron con amarillo lucifer a una concentración de $0,5 \mathrm{mg} / \mathrm{ml}$ y se observaron por microscopía de fluorescencia. A. Macrófago control, microscopía de luz. B. Macrófago control, 5 minutos y C. Macrófago control, 20 minutos después de la carga de la sonda. D. Vacuolas parasitóforas aisladas, microscopía de luz. E. Vacuolas parasitóforas, 15 minutos después de la carga y $\mathrm{F}$. Vacuolas parasitóforas, 15 minutos después de la carga de la sonda en presencia de $5 \mu \mathrm{M}$ de probenecid. G. Macrófagos infectados por L. amazonensis, 48 horas después de la infección, microscopía de luz. H. Macrófagos infectados por L. amazonensis, 48 horas después de la infección, 10 minutos después de la carga de la sonda. I. Macrófagos infectados por L. amazonensis, 48 horas después de la infección, microscopía de luz. J. Macrófagos infectados por L. amazonensis, 48 horas después de la infección, 30 minutos después de la carga. K. Macrófagos infectados por L. amazonensis, 48 horas después de la infección, microscopía de luz y L. 30 minutos después de la carga de la sonda en presencia de $5 \mu \mathrm{M}$ de probenecid. M. Macrófago luego de la fagocitosis de partículas de látex, microscopia de luz. N. Macrófagos luego de fagocitosis de partículas de látex, 10 minutos después de la carga. O. Macrófago luego de la fagocitosis de partículas de látex, microscopia de luz. P. Macrófago luego de la fagocitosis de partículas de látex, 30 minutos después de la carga. Q. Macrófago luego de la fagocitosis de partículas de látex, microscopía de luz. R. Macrófago luego de la fagocitosis de partículas de látex, 30 minutos después de la carga en presencia de de $5 \mu \mathrm{M}$ de probenecid. Los datos son experimentos representativos de 10 experimentos.

Barra: en D-F, $5 \mu \mathrm{m}$ y $8 \mu \mathrm{m}$ para las demás imágenes; vp: vacuola parasitófora; flechas: parásitos. 
calceína. Se tuvo en cuenta la distribución de la sonda en el citoplasma y, en el caso de macrófagos que fagocitaron látex o fueron infectados, se observó la concentración o exclusión de las sondas en la luz del fagosoma o de la vacuola parasitófora, respectivamente.

La sonda amarillo lucifer no atraviesa la membrana celular; por ello fue necesario cargarla permeabilizando la membrana plasmática del macrófago con ATP (11). En los macrófagos control (figura 2A), se observó el amarillo lucifer distribuido de manera uniforme por todo el citoplasma a los 5 minutos después de la carga (figura 2B). Luego, entre los 10 y los 45 minutos después de la carga, la sonda se concentró en compartimientos citoplasmáticos o fue liberada al medio extracelular (figura $2 \mathrm{C}$ ).

La permeabilidad de la vacuola parasitófora de Leishmania (figuras 2D, 2E, 2F) no presentó diferencias con el patrón observado en los macrófagos control, aunque fue un proceso relativamente más lento. En las células infectadas, a los 10 minutos después de la carga, el amarillo lucifer se observó en el citoplasma y en el núcleo, pero fue excluida de la vacuola parasitófora (figuras $2 \mathrm{G}, 2 \mathrm{H}$ ). Después de 30 minutos de la carga, la sonda se encontró en las vacuolas parasitóforas y en pequeñas vesículas citoplasmáticas pero no en el citoplasma (figuras 2I, 2J).

El inhibidor probenecid bloqueó la transferencia de amarillo lucifer a la luz de la vacuola parasitófora (figuras $2 \mathrm{~F}, 2 \mathrm{~K}, 2 \mathrm{~L}$ ). La distribución de amarillo lucifer en fagosomas de partículas de látex fue similar a los controles (figuras $2 \mathrm{M}-2 \mathrm{P}$ ). La concentración de la sonda en el fagosoma se puede atribuir a un transportador $A B C$ porque la presencia de probenecid, un inhibidor de este grupo de moléculas, evita esta distribución (figuras 2Q, 2R).

Por encontrarse en su forma acetoximetil éster, la calceína/AM permea fácilmente las membranas celulares interactuando con los lípidos de la membrana. En este estado, la sonda no es
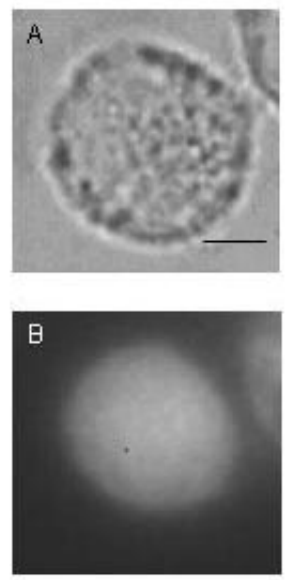
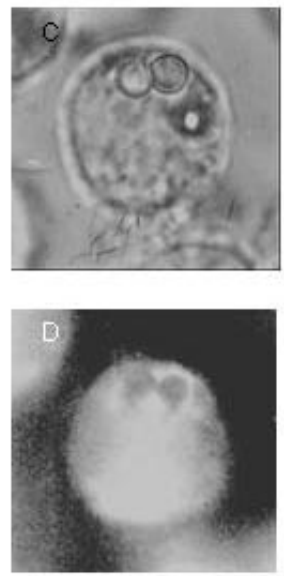
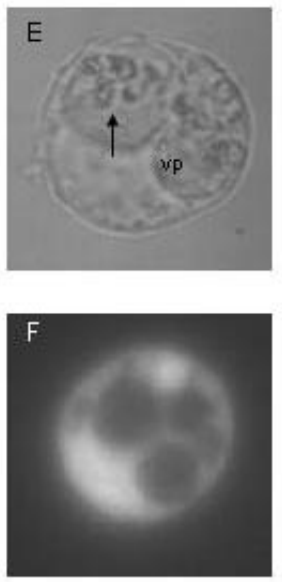
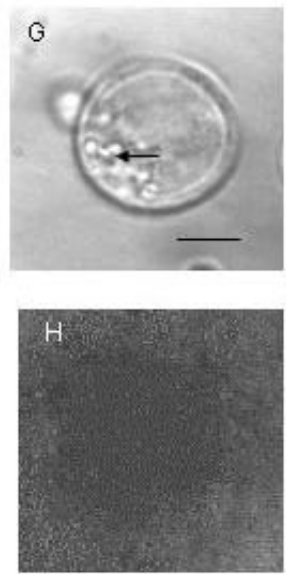
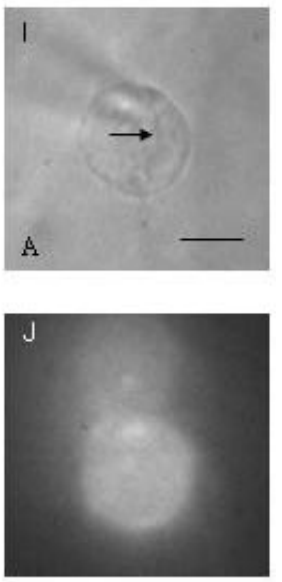

Figura 3. Permeabilidad de la vacuola parasitófora a través de trasportadores $A B C$ determinada por distribución de la sonda fluorescente calceína. Células J774.A1 control, luego de fagocitosis de partículas de látex, infectadas por $L$. amazonensis, o vacuolas parasitóforas aisladas se cargaron con calceína a una concentración de $25 \mu \mathrm{M}$ y se observaron por microscopía de fluorescencia. A. Macrófago control, microscopía de luz. B. Macrófago control, después de la carga de la sonda. C. Macrófagos luego de la fagocitosis de partículas de látex, microscopia de luz. D. Macrófagos luego de fagocitosis de partículas de látex después de la carga de la sonda. E. Macrófagos infectados por L. amazonensis 48 horas después de la infección, microscopia de luz. F. Macrófagos infectados por L. amazonensis 48 horas postinfección, después de la carga de la sonda. G. e I. Vacuolas parasitóforas aisladas, microscopía de luz. H. Vacuolas parasitóforas aisladas, después de la carga de la sonda. J. Vacuolas parasitóforas aisladas, después de la inyección de la sonda con pipeta de vidrio. Los datos son experimentos representativos de 10 experimentos.

Barra en A-F: $8 \mu \mathrm{m}$, en G-H, $5 \mu \mathrm{m}$ y en I y J $6 \mu \mathrm{m}$; vp: vacuola parasitófora; flechas: parásitos 

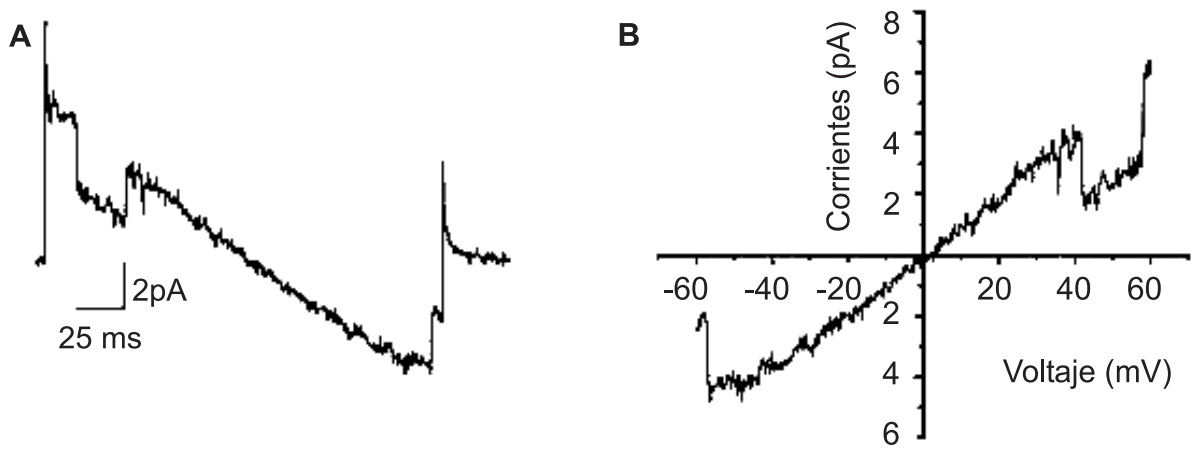

Figura 4. Permeabilidad de la VP mediada por corrientes iónicas.

VP aisladas fueron registradas con la técnica de patch-clamp en configuración de VP-adherida. A. Curva de corriente contra tiempo de un registro obtenido luego de la aplicación de una rampa de voltaje desde 60 hasta $-60 \mathrm{mV}$ desde un potencial de sostenimiento de $0 \mathrm{mV}$. B. Curva IV de donde se observa potencial de reversión de 1,6 mV. Los datos son experimentos representativos de 7 VP registradas. El potencial de reversión se relaciona con el potencial de equilibrio de los iones que pasan a través de la corriente detectada.

fluorescente; una vez ingresa en el citoplasma, los grupos éster son cortados por esterasas y la sonda pasa a su forma fluorescente. Por este mecanismo la calceína puede ser usada para determinar la viabilidad celular.

En los macrófagos control (figura 3A), entre los 5 y los 60 minutos después de la carga, la calceína se distribuye por todo el citoplasma de manera uniforme y no es liberada al medio exterior (figura 3B). En las células que fagocitaron látex (figura 3C), la sonda se observó por todo el citoplasma, pero fue excluida del fagosoma (figura 3D). De la misma manera, en macrófagos infectados (figura $3 \mathrm{E}$ ), las vacuolas parasitóforas excluyeron por completo la sonda en todos los tiempos después de la infección (figuras 3F, 3G, 3H), lo cual sugiere que no existe ningún mecanismo de transporte de calceína hacia el exterior del macrófago, la luz del fagosoma o de la vacuola parasitófora.

\section{Permeabilidad de la vacuola parasitófora aislada}

El aislamiento de vacuolas parasitóforas se llevó a cabo siguiendo el método recomendado por Chakraborty et al. (8) y usado por Schaible et al. (3), para Leishmania mexicana. La separación se siguió por microscopía de luz y enriquecimiento de la actividad de la enzima $\beta$-glucoronidasa, un marcador lisosómico. En las fracciones separadas, las vacuolas parasitóforas se identificaron por su tamaño, apariencia de la membrana y presencia de amastigotes. Se definió como vacuolas parasitóforas a toda estructura con diámetro alrededor de $10 \mu \mathrm{m}$ y con parásitos en su interior, adosados a la membrana del compartimento.

Debido a que las vacuolas parasitóforas aisladas con esta metodología presentaban morfología anormal y alteraciones de las propiedades de permeabilidad de su membrana que atribuimos al efecto osmolar ejercido por la sacarosa, se sustituyó parte de la sacarosa por un gradiente discontinuo de Percoll, así: un colchón inferior de $60 \%$ de sacarosa y colchones de $1 \mathrm{ml}$ de Percoll que variaron de la siguiente manera: 40-30-15. Las vacuolas parasitóforas aisladas se encontraron en la interfase entre los colchones de 10\% y $20 \%$ de Percoll, fracciones en las cuales se acumuló el $41 \%(22 \%$ y $19 \%$, respectivamente) de la actividad de $\beta$-glucoronidasa. Los datos reportados a continuación se hicieron en vacuolas parasitóforas aisladas utilizando el gradiente de Percoll de 40-20-10\%.

La vacuola parasitófora in situ, colorea de rojo con la sonda naranja de acridina lo cual indica la presencia de un $\mathrm{pH}$ ácido. Este gradiente de $\mathrm{pH}$ se mantiene aún después del aislamiento de 
vacuolas parasitóforas (figura $1 \mathrm{H}$ ) lo que sugiere que la membrana de la vacuola parasitófora no presenta alteraciones importantes de permeabilidad que lo disipen. En la figura $1 \mathrm{H}$ la marcación verde en el cuadrante inferior izquierdo de la vacuola parasitófora indica la marcación de ácidos nucleicos y sugiere la presencia de Leishmania. Como se describió para las vacuola parasitófora in situ, el amarillo lucifer se concentró en la vacuola parasitófora (figura 2E) y este proceso fue mediado por un transportador $A B C$ ya que la presencia del inhibidor probenecid evitó el transporte de la sonda la luz de la vacuola parasitófora (figura 2F). La presencia del gradiente de protones y el transporte de amarillo lucifer sugiere, además, que las vacuolas parasitóforas aisladas son capaces de mantener procesos dependientes de la hidrólisis de ATP.

El transporte de la sonda calceína también fue restringido por vacuolas parasitóforas aisladas (figura $3 \mathrm{H}$ ) y la exclusión no es debida a alteraciones en la capacidad de emisión de la sonda en un compartimento ácido, ya que es posible visualizarla luego de su inyección directa (figuras 3I, 3J).

\section{Detección de corrientes iónicas en vacuolas parasitóforas aisladas}

Las técnicas electrofisiológicas se usan para la caracterización de las propiedades eléctricas de la membrana. El uso de esta técnica en membranas de compartimientos intracelulares es escaso. Los estudios aquí reportados se hicieron sobre grupos de vacuolas parasitóforas provenientes de aislamientos en los que se había hecho verificación de la presencia del parásito por observación en microscopía y en los que las marcaciones con naranja de acridina y amarillo lucifer eran satisfactorios.

Usando la técnica de patch clamp (10) en la configuración de vacuola parasitófora adherida y en soluciones con concentraciones iónicas simétricas se lograron sellos de alta resistencia (>1G $\Omega$ ). Estos sellos fueron de difícil obtención por las dificultades para inmovilizar las vacuolas parasitóforas y la fragilidad de este compartimento. No se lograron registros en la configuración de vacuola parasitófora completa. Por lo tanto, los datos presentados corresponden a vacuolas parasitóforas en configuración de vacuola parasitófora adherida, en las que se registran las corrientes a través de los canales iónicos presentes en la zona de la membrana en donde se ubica la pipeta de registro, y provenientes de 7 vacuolas parasitóforas.

Las vacuolas parasitóforas se estimularon con rampas de potencial desde 60 hasta $-60 \mathrm{mV}$ que se usan para detectar todas las corrientes iónicas presentes. Las corrientes observadas se favorecen a diferencias de potencial de $55 \pm 1,5$ $m V$ (figura 4A) en la que se observa una deflexión que corresponde a la apertura y cierre de la corriente registrada. El promedio de corriente cuando se observaron aperturas fue de 2,5 $\pm 0,3$ pA $(n=20)$ y la conductancia calculada fue de $46 \pm 3$ $p S(n=20)$. La curva IV que relaciona la corriente con el voltaje que la activa, muestra que el potencial de reversión, potencial al cual la corriente neta es igual a 0 y que al relacionarse con el potencial de equilibrio para los iones presentes indica cuál es el ión que permea, es cercano a 0 lo que sugiere poca selectividad (figura 4B).

\section{Discusión}

La vacuola parasitófora que contiene a Leishmania parece satisfacer los requerimientos nutricionales del parásito y soporta su crecimiento y replicación. Los datos obtenidos durante el presente estudio sugieren que las vacuolas parasitóforas de Leishmania amazonensis pueden transportar iones desde el citosol de la célula hospedera.

El secuestro de la sonda amarillo lucifer (521 da) en la luz de la vacuola parasitófora de $L$. mexicana se ha atribuido a la presencia de transportadores de aniones de la familia de glicoproteínas transportadoras $A B C$ en la membrana de dicho organelo $(2,3)$ y confirmada en las vacuolas parasitóforas de $L$. amazonensis en el presente estudio (figuras 2F, 2L). Representantes de la familia de transportadores $A B C$ o Pgp son capaces de transportar un rango de sustratos heterogéneo. Se ha descrito el transporte de carboxifluoresceína (376 da) hacia el interior de vacuolas citosólicas y hacia el medio extracelular en macrófagos peritoneales de ratón, y atribuido a la presencia 
de transportadores $A B C$ sensibles a probenecid, incluidos en la membrana celular y vacuolar (12).

Este tipo de transportadores expresados en la membrana de macrófagos de ratón pueden secretar antibióticos como penicilina G (546 da) y norfloxacina (320 da) $(13,14)$ y su inhibición disminuye la producción de IL-12, y la regulación de moléculas MHC II (15). Se encuentran, además, en células tumorales humanas (16) y en Leishmania (17), están implicados en el transporte de aniones orgánicos como urato y $\mathrm{p}$-aminohipurato (16) y en el transporte de tioles y metales (17).

Muchas moléculas sintetizadas por los macrófagos son empacadas en vesículas y liberadas luego de la fusión de éstas con la membrana plasmática. Transportadores como los aquí reportados podrían estar mediando la transferencia de moléculas aniónicas, cuyos pesos moleculares oscilan entre 350 y 600 da, de cuya vía secretora no se conoce nada. Entre estas moléculas aniónicas se encuentran leucotrienos y prostaglandinas que juegan un papel importante en las respuestas inmune e inflamatoria, glutatión, bilirrubina y lactato producido durante la glucólisis (18). Los transportadores de aniones podrían funcionar como sistema de concentración de pequeños productos orgánicos, péptidos y toxinas, para ser exportados de la célula vía exocitosis.

La exclusión de una molécula del tamaño de la calceína de fagosomas de partículas de látex y de vacuolas parasitóforas de $L$. amazonensis se observó por primera vez en el presente estudio. En el citoplasma, la calceína/AM se convierte en un derivado polianiónico de la fluoresceína, el cual emite fluorescencia al perder sus grupos éster por la acción de esterasas inespecíficas. La pérdida de los grupos éster hace que la molécula pierda movilidad a través de membranas, quedando atrapada en el citosol. Podría ser concentrada en la luz de los fagosomas y vacuolas parasitóforas, pero los trasportadores presentes (figuras $2 \mathrm{~J}, 2 \mathrm{P}$, 3D, 3F) no permiten su paso, probablemente, por el tamaño.

Así mismo, las sondas fluorescentes fluo-3 (781 da) y fura-2 (832 y $880 \mathrm{da}$ ) no se equilibran entre el citoplasma y la vacuola parasitófora de macrófagos infectados con L. amazonensis (19), pero se ha observado que fura-2 marca otros compartimentos endosómicos $(6,19,20)$.

La vacuola parasitófora de Chlamydia trachomatis excluye la calceína (21) y en fibroblastos infectados con Toxoplasma gondii, los péptidos y las moléculas de más de 1.900 da no cruzan la membrana de la vacuola parasitófora (22). Esto nos permite especular que los fagosomas de partículas de látex y las vacuolas parasitóforas de L. amazonensis no interactúan con algunos compartimentos endosómicos excluyendo en este proceso la expresión de trasportadores aniónicos como los que concentran fluo y fura-2.

Los estudios presentados en vacuolas parasitóforas aisladas confirman los hallazgos in situ y la evidencia previa $(2,3)$. Sin embargo, este es el primer estudio en el que se presenta evidencia microscópica de luz de vacuolas parasitóforas aisladas demostrando algunas de sus propiedades de permeabilidad, aunque Kima y Dunn (23) muestran la ultraestructura de vacuolas parasitóforas purificadas usando el marcador calnexín. Sugerimos que las modificaciones hechas en el proceso de purificación de este compartimento, es decir, el reemplazo por un gradiente de Percoll, mejoran el aislamiento de las vacuolas parasitóforas.

Este estudio, además, reporta por primera vez datos electrofisiológicos obtenidos de vacuolas parasitóforas aisladas. Estudios previos con esta técnica en eritrocitos infectados con Plasmodium falciparum (24), registran una conductancia a aniones, aunque no queda claro si los registros se obtuvieron de la membrana del eritrocito o de la vacuola parasitófora que contiene Plasmodium. A pesar de esto, existe evidencia que argumenta a favor de cambios en la permeabilidad del eritrocito por modificación de canales iónicos constitutivos de su membrana $(25,26)$ y por expresión de transportadores de origen parasitario $(26,27)$.

La conductancia calculada a partir de la corriente registrada en la membrana de la vacuola parasitófora aislada (figura 4) podría ser el resultado de la expresión de un transportador $A B C$, canales iónicos del retículo endoplasmático del macrófago o porinas. La presencia de trans- 
portadores $A B C$ ha sido documentada en compartimentos de la vía endocítica de macrófagos control e infectados y en la membrana de la vacuola parasitófora $(2,3)$ (figuras $2 F, 2 L$, $2 \mathrm{R})$. La evidencia reciente que sugiere que la membrana del retículo endoplasmático (28) es incorporada para la formación de fagosomas, abre la posibilidad que los canales de calcio dependientes de ligando y voltaje, presentes en la membrana de este compartimento (18), puedan estar asociados con la membrana de la vacuola parasitófora.

En cuanto a la presencia de porinas se sabe que los protozoarios Trypanosoma cruzi y Entamoeba histolytica $(29,30)$, expresan proteínas con características similares a estas moléculas. Más aún, los promastigotes de L. amazonensis contienen una hemolisina capaz de causar lisis coloidosmótica de eritrocitos, y extractos de este parásito que contienen esta actividad reaccionan con anticuerpos contra perforina y C9 mostrando que Leishmania también sintetiza porinas. Noronha et al. sugieren que esta porina estaría mediando la salida de Leishmania del macrófago (31).

Nuestros hallazgos electrofisiológicos no nos permiten determinar el tipo de molécula que genera la corriente registrada y su significado fisiológico. Sin embargo, la expresión de porinas puede ser un mecanismo de entrada de iones y nutrientes a través de la membrana de la vacuola parasitófora como se ha sugerido para otros parásitos $(22,24)$, parte del proceso de salida del parásito (32) o servir en la exclusión de péptidos del parásito limitando así presentación de antígeno.

Los estudios futuros incluyen la caracterización electrofisiológica de la corriente descrita en la membrana de la vacuola parasitófora, la determinación de su origen y su función. Los trabajos de los mecanismos de adquisición de moléculas por la vacuola parasitófora contribuirán al entendimiento de la nutrición, la supervivencia y el desarrollo del parásito en infecciones in vitro e in vivo. Más aún, la investigación del transporte de fármacos a través de la vacuola parasitófora que contiene a Leishmania podría ser de gran valor, por ser este compartimento un sitio blanco para la quimioterapia.

\section{Agradecimientos}

Agradecemos a las entidades que financiaron este trabajo, al Departamento de Biología de la Facultad de Ciencias de la Universidad Nacional de Colombia, sede Bogotá, y al Centro Internacional de Física de Bogotá, Colombia.

\section{Conflicto de intereses}

Los autores de este manuscrito garantizamos que no tenemos conflicto de intereses.

\section{Financiación}

Este trabajo fue financiado por: Colciencias, proyecto: 2228-04-12899, Programa Nacional de Ciencia y Tecnología de la Salud; División de Investigaciones, proyecto: 903835, Universidad Nacional de Colombia; Joselín Hernández recibió apoyo de la DINAIN (División Nacional de Investigaciones, Universidad Nacional de Colombia), programa apoyo a estudiantes: DI00C352.

\section{Referencias}

1. Antoine JC, Prina E, Jouanne C, Bongrand P. Parasitophorous vacuoles of Leishmania amazonensisinfected macrophages maintain an acidic $\mathrm{pH}$. Infect Immun 1990;58:779-87.

2. Russell DG, Xu S, Chakraborty P. Intracellular trafficking and the parasitophorous vacuole of Leishmania mexicana-infected macrophages. J Cell Sci 1992;103:1193-210.

3. Schaible UE, Schlesinger PH, Steinberg TH, Mangel WF, Kobayashi T, Russell DG. Parasitophorous vacuoles of Leishmania mexicana acquire macromolecules from the host cell cytosol via two independent routes. J Cell Sci 1999;112:681-93.

4. Sturgill-Koszycki S, Schlesinger $\mathbf{P H}$, Chakraborty P, Haddix PL, Collins HL, Fok AK et al. Lack of acidification in Mycobacterium phagosomes produced by exclusion of the vesicular proton-ATPase. Science 1994;263:678-81.

5. Lipman BJ, Silverstein SC, Steinberg TH. Organic anion transport in macrophage membrane vesicles. $\mathrm{J}$ Biol Chem 1990;265:2142-7.

6. Cortázar T. Estudios de permeabilidad del fagosoma que contiene al protozoario Leishmania amazonensis (trabajo de grado). Bogotá: Universidad Nacional de Colombia; 2000.

7. Hernández J. Permeabilidad de membrana del compartimiento que contiene a Leishmania mexicana amazonensis en macrófagos J774.1 (trabajo de grado). Bogotá: Universidad Nacional de Colombia; 2001. 
8. Chakraborty P, Sturgill-Koszycki S, Russell DG. Isolation and characterization of pathogen-containing phagosomes. Methods Cell Biol 1994;45:261-76.

9. Lang T, Hellio R, Kaye PM, Antoine JC. Leishmania donovani-infected macrophages: characterization of the parasitophorous vacuole and potential role of this organelle in antigen presentation. J Cell Sci 1994;107:2137-50.

10. Hamill OP, Marty A, Neher E, Sakmann B, Sigworth FJ. Improved patch-clamp techniques for high-resolution current recording from cells and cell-free membrane patches. Pflugers Arch 1981;391:85-100.

11. Steinberg TH, Newman AS, Swanson JA, Silberstein SC. ATP4- permeabilizes the plasma membrane of mouse macrophages to fluorescent dyes. J Biol Chem 1987;262:8884-8.

12. Steinberg TH, Newman AS, Swanson JA, Silverstein SC. Macrophages possess probenecidinhibitable organic anion transporters that remove fluorescent dyes from the cytoplasmic matrix. J Cell Biol 1987;105:2695-702.

13. Cao CX, Silverstein SC, Neu HC, Steinberg TH. J774 macrophages secrete antibiotics via organic anion transporters. J Infect Dis 1992;165:322-8.

14. Cao C, Steinberg TH, Neu HC, Cohen D, Horwitz SB, Hickman S et al. Probenecid-resistant J774 cell expression of enhanced organic anion transport by a mechanism distinct from multidrug resistance. Infect Agents Dis 1993; 2:193-200.

15. Hasko G, Deitch EA, Nemeth ZH, Kuhel DG, Szabo C. Inhibitors of ATP-binding cassette transporters suppress interleukin-12 p40 production and major histocompatibility complex II up-regulation in macrophages. J Pharmacol Exp Ther 2002,301:103-10.

16. Efferth T, Lohrke H, Volm M. Reciprocal correlation between expression of P-glycoprotein and accumulation of rhodamine 123 in human tumors. Anticancer Res 1989;9:1633-7.

17. Légaré D, Richard D, Mukhopadhyay R, Stierhof YD, Rosen BP, Haimeur A et al. The Leishmania ATPbinding cassette protein PGPA is a intracellular metalthiol transporter ATPase. J Biol Chem 2001;276:263017.

18. Alberts B, Johnson A, Lewis J, Raff M, Roberts K, Walter P. Membrane transport of proteins of small molecules and the electrical properties of membranes. En: Alberts B, Johnson A, Lewis J, Raff M, Roberts K, Walter P, editors. Molecular biology of the cell. Fourth edition. New York: Garland Sience; 2002. p.615-57.

19. Montes M. Estudio de conductancias iónicas y determinación de la concentración intracelular de calcio en macrófagos murinos infectados por Leishmania amazonensis (tesis). Bogotá: Universidad Nacional de Colombia; 1995.

20. Di Virgilio F, Steinberg TH, Silverstein SC. Inhibition of Fura-2 sequestration and secretion with organic anion transport blockers. Cell Calcium 1990;11:57-62.

21. Heinzen RA, Hackstadt T. The Chlamydia trachomatis parasitophorous vacuolar membrane is not passively permeable to low-molecular-weight compounds. Infect Immun 1997;65:1088-94.

22. Schwab JC, Beckers C, Joiner KA. The parasitophorous vacuole membrane surrounding intracellular Toxoplasma gondii functions as a molecular sieve. Proc Natl Acad Sci USA 1994;91:509-13.

23. Kima PE, Dunn W. Exploiting calnexin expression on phagosomes to isolate Leishmania parasitophorous vacuoles. Microb Pathog 2005;38:139-45.

24. Desai SA, Krogstad DJ, McCleskey E. A nutrientpermeable channel on the intraerythrocytic malaria parasite. Nature 1993;362:643-6.

25. Huber SM, Duranton C, Henke G, van De Sand C, Heussler V, Shumilina E et al. Plasmodium induces swelling-activated $\mathrm{CIC}-2$ anion channels in the host erythrocyte. J Biol Chem 2004;279:41444-52.

26. Ginsburg H, Stein WD. How many functional transport pathways does Plasmodium falciparum induce in the membrane of its host erythrocyte? Trends Parasitol 2005;21:118-21.

27. Staines HM, Powell T, Thomas SL, Ellory JC. Plasmodium falciparum-induced channels. Int $\mathrm{J}$ Parasitol 2004;34:665-73.

28. Gagnon E, Duclos S, Rondeau C, Chevet E, Cameron PH, Steele-Mortimer $\mathrm{O}$ et al. Endoplasmic reticulum-mediated phagocytosis is a mechanism of entry into macrophages. Cell 2002;110:119-31.

29. Andrews NW. The acid-active hemolysin of Trypanosoma cruzi. Exp Parasitol 1990;71:241-4.

30. Leippe M, Muller-Eberhard HJ. The pore-forming peptide of Entamoeba histolytica, the protozoan parasite causing human amoebiasis. Toxicology 1994;87:518.

31. Noronha FS, Ramalho-Pinto FJ, Horta MF. Identification of a putative pore-forming hemolysin active at acid $\mathrm{pH}$ in Leishmania amazonensis. Braz $\mathrm{J}$ Med Biol Res 1994;27:477-82.

32. Almeida-Campos FR, Horta MF. Proteolytic activation of leishporin: evidence that Leishmania amazonensis and Leishmania guyanensis have distinct inactive forms. Mol Biochem Parasitol 2000;111:36375 . 